\title{
Pedagogical Knowledge in Mathematics: A Challenge of Mathematics Teachers in Secondary Schools
}

\author{
Gunendra Chandra Das
}

\begin{abstract}
The research reported in this article is a study that examines teachers' limitations in expanding their expertise in facilitating mathematical problem solving through effective pedagogy. For the study twelve mathematics teachers having teaching experience from different secondary schools of Kamrup district were approached and five of them consented to join the programunder the study. They were interviewed, asked to teacha topic of geometry in ninth standard. Traditional pedagogies of teachers'explanation followed by student practice have been found among them with poor or no formal lesson plan. Interview episode reflects their confidence in teaching, albeit agreed to have deficiency of pedagogical knowledgeof mathematics in general and particularly in geometry.
\end{abstract}

Index Terms-Content knowledge, mathematics teaching, pedagogy.

\section{INTRODUCTION}

The most international of all curriculum subjects in schools is mathematics, and the understanding in this subject influences decision making everywhere of our life. Mathematics education plays a key role in increasing the post-school opportunities of young minds, but today, many students are struggling with mathematics and being disaffected as they continually encounter various obstacles for engagement. Therefore, what effective mathematics teaching help students come to understand, and be able to use mathematics is really a great challenge for teachers.

Mathematics education during the last three decades perspectives has been promoted developing an understanding of mathematical concepts, procedures and applications through problem solving [1]-[3]. However, pedagogical development in mathematical understanding through problem solving still remains as a challenge for teachers.Mathematics pedagogy focuses on the ways in which teachers help their students come to understand and be able to use mathematics in different areas.

What does an efficient mathematics teacher mean? What should be the qualities for him or her? There is a common belief that those who learn moremathematics and familiar with higher difficulty level problems they are good.But, which is not necessarily true. In the research report [4], [5] and [6] as cited in [7] no co-relation between teachers' contentknowledge in mathematics and their students' successin mathematics was found.

Manyresearchers already reported various effective descriptions on teachers' roleduring the classroomsession

Manuscript received May 29, 2014; revised July 30, 2014.

Gunendra Chandra Das is with the Assam down town University, Guwahati, India (e-mail: gicidas@gmail.com). about motivation, interaction, uses of models, problem solving devices etc. All these can be considered as mainly two types of knowledge-firstly, mathematical content knowledge which enhances capability to explain and interact to students' doubts; secondly, pedagogical content knowledge through which students achieve knowledge with proper understanding and applicability.Pedagogical content knowledge asserts that knowing what and knowing how are inseparable in the business of effective teaching. Pedagogical knowledge in mathematics is the device of transition from contents to its applicability. How the relationship between the contents and everyday life activities could be presented before students during class room session is enhanced by this type of knowledge.Pedagogical content knowledgewas expoundedin [8] and defined the concept as 'that special amalgam of content and pedagogy that is uniquely the province of teachers, their own special form of professional understanding,reported in [9].

The most significant during the classroom session is the teacher's guidance on direction, supervision, and rhythm of classroom activities by deciding instantly what questions to put, how to present the issues, to relate with physical phenomena.In pedagogical point of view teachers in mathematics have a very critical role to play in facilitating students for effective learn.The teachers have to introduce a topic in different manners explaining reasons about its existence and applicability through some activities, like models, small group discussion, asking questions which push students to examine and articulate their ideas. It can be difficult to grasp a new concept or solve a problem when distracted by the views of others. That is why, teachers should ensure that all students are given opportunities to think and work quietly by themselves, where they are not required to process the varied, sometimes conflicting perspectives of others.

In the mid-1980s when [8], [10], introduced the notion of pedagogical content knowledge then the study of teacher knowledge was revitalized. Although the term was not clearly defined at the beginning, the very notion of specialized content-related knowledge forteaching caught the Schoenfield's [11] imagination and opened up significant new arenas for both research and practice.

\section{MAthematical Pedagogy}

Researchers defined and interpreted pedagogy in mathematics teaching in different ways to focus how it is significantly important for quality learning outcome.New research is defining pedagogy as "a highly complex blend of theoretical understanding and practical skill” [9]. 
Mathematical pedagogy explicitly emphasizes not only the substance of mathematics butalso its nature and epistemology [12] which assumes that students must be actively involved in constructingtheir own understandings, in discovering and inventing mathematics. The basis for thisemerges directly from a largely constructivist epistemology of the discipline, [13].

Whatever pedagogical strategies teachers believe, their role is always a determinant factor of effective classroom session. "Teacher quality is the single greatest factor in explaining student achievement, more important than classroom related issues such as resources, curriculum guidelines and assessment practices, or the broader school environment such as school culture and organisation" [9].With the reference of [14] on 'pedagogy for future' it has been reported distinctly in [15] that the quality of student learning outcomes is directly dependent on the quality of the teacher; and, the essential components of effective teaching are command of subject, and knowledge of capacity to implement effective pedagogical practices. How effective pedagogical practices could be developed is depicted through radial cycle in Fig. 1.

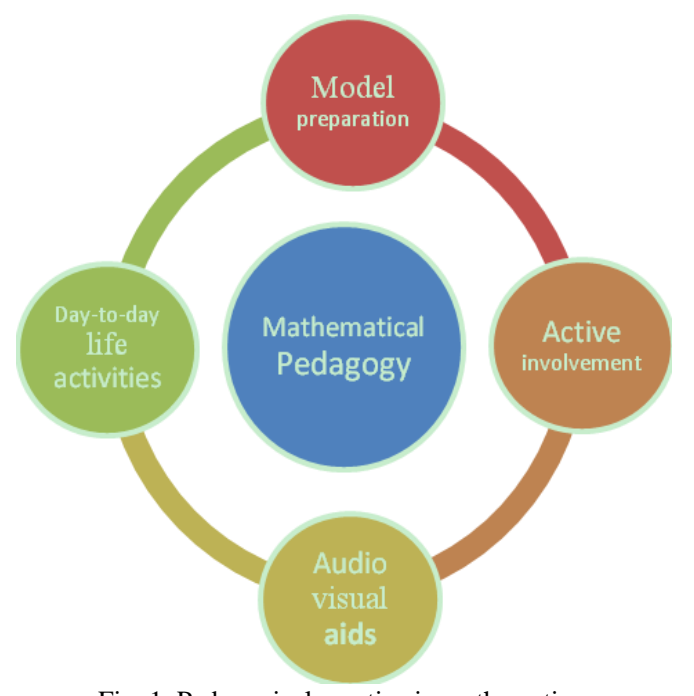

Fig. 1. Pedagogical practice in mathematics.

\section{GEOMETRY IN MATHEMATICS}

Geometry is one of the most important branches of mathematics which deals with the various properties and relationships of lines, planes, angles, curves, surfaces etc. in any dimension. It helps students in visualizing diagrammatical interpretations, systematic describing and defining and making connections mathematical knowledge with the day to day life activities."Geometry and spatial sense are fundamental components of mathematics learning. They offer ways to interpret and reflect on our physical environment." Which has been stated in the National Council of Teachers of Mathematics [2], emphasizing the importance of geometry in school Mathematics.

It is significantly important to develop geometric reasoning in middle school level to bring the students into their comfort zone for secondary level. According to the theory of Pierre and Dina Van Hiele, students' progress through levels of thought is in geometry [16], [17]. Based on their studies five developmental levels of geometric reasoning have been reported in [18] which are:

- Level 0 (Basic Level): Visualization

At this level students view objects as entire entities, not noticing individual components orproperties. The focus is on the whole object, not its parts.

- Level 1: Analysis

Students begin to recognize that geometric shapes have parts and special properties. However, theyare not able to describe how these properties are related, nor they able to understand definitions.

- Level 2: Informal Deduction

At this level students comprehend the connection between properties within geometric figures andfrom one set of figures to another. Students are able to follow proofs, but are not able to constructionthemselves.

- Level 3: Deduction

At this level students can construct a geometric proof and understand the connection betweenpostulates, theorems, and undefined terms.

- Level 4: Rigor

At this level students see geometry in the abstract. Students can move between different geometricsystems and can compare and contrast them.

For the development of students' geometric reasoning undoubtedly, these developmental levels are useful during teaching session if students have a positive attitude towards geometry and which can be shaped with the teachers' positive attitude and his/her effective pedagogical content knowledge. Teachers' method of geometry teaching and his/her personality greatly accounted for the students' positive attitude towards geometry and that without interest and personal effort in learning geometry by the students, they can hardly perform well in the topic, which has been revealed in [19]. As a part of pedagogical skill teachers' instructions is one of the important factors for students' learning geometry.

\section{STUDY}

The study investigated how five secondary school mathematicsteachers in the district of Kamrupprepared for the daunting task of teaching a geometry class of ninth standard in secondary school. Their preparation and teachingmay indicate how they experience need to develop pedagogical knowledge in mathematics particularly, in a geometrical topic. Several questions have been considered to guide the investigation.

1) Do the teachers really understand mathematical pedagogy?

2) How do they emphasize on pedagogical knowledge during classroom session?

3) Howthe teachers prepare pedagogical content knowledge for classroom session?

4) Dothe teachers evaluate themselves from students feed-back?

5) Do the teachers prepare exclusively for geometrical topic?

6) Do the teachers experience different while start teaching geometry?

7) Do the teachers believe in experience to develop pedagogical skill? 


\section{Methodology}

For the study twelve experienced mathematics teachers from various secondary and senior secondary schools under CBSE (Central Board of Secondary Education) and SEBA (Board of Secondary Education Assam) were approached and five of them consented to join the assessment program under the study.Out of them three were having B Ed (Bachelor of Education), a teachers raining program and considered them as trained teachers. A test comprising various difficulty leveled problems was conducted among them to assess their level of mathematical content knowledge. They were asked to teach a topic of geometry for a period of 30 minutes in ninth standard in presence of 26 studentsfollowed by an interview with them. After occurrence of the test they were requestedindividually to submit a lesson plan after one week on a lesson from geometry section of ninth standard to supervise what and how they introduce with a new pedagogical approach and implement it during entire classroom session. When the teaching period is over,students' feed-back were sought orally and recorded against each of the teachers in absence of them. Next day, they have been interviewed on their experience and perception towards the importance of pedagogical content knowledgeduring a class room session. From pedagogical point of view the questions were placed to extract their concept on the knowledge they needed for teaching mathematics.

\section{RESULTS}

The test scores of the 5 teachers reveal variety of performance which reflects their content knowledge in mathematics and preparation. Out of 10 the scores obtained by the teachers with highest score 7and the lowest was 2 were recorded as in the Table I.

TABLE I: CONTENT KNOWLEDGE ASSESSMENT

\begin{tabular}{|c|c|c|c|c|}
\hline Teachers & Gender & Age in years & Teaching experience & Test score \\
\hline $\mathbf{T}_{1}$ & Male & 26 & 3 years & 4 \\
\hline $\mathbf{T}_{2}$ & Female & 28 & 6 years & 3 \\
\hline $\mathbf{T}_{3}$ & Male & 30 & 9 years & 7 \\
\hline $\mathbf{T}_{4}$ & Female & 27 & 5 years & 2 \\
\hline $\mathbf{T}_{5}$ & Male & 31 & 10 years & 4 \\
\hline
\end{tabular}

The result shows that in one hand despite the teachers $T_{2}$, $\mathrm{T}_{4}, \mathrm{~T}_{5}$ having 5 to 10 years experience, they were low level performer with scores 2 to 4 , on the other hand one of them with score 4 and another one with score 7 showed good performance.

\section{A. Results of Interviews}

When they were asked about their preparation all of them expressed dissatisfaction regarding the test, because of their preparation was regarding actual teaching job. All of them acknowledged that their previous teaching experience helped them in taking class confidently. One of them said about the necessity of a brief course work on the program. Three of them acknowledged about the necessity of preparation for geometry lesson. Most of them stated that the art of teaching geometry is different from the same for other mathematical topics; however, for that preparation was not required exclusively other than a little bit mental preparedness.

When asked whether they like teaching geometry or not, most of them disliked, but one, who scored highest liked it and stated significantly that progression of geometric reasoning and the connectivity with the theorems, postulates, axioms are two most important and difficult tasks during class room session in geometry.As a result, most of the students are unable to approach a new geometrical problem. During class room session in geometry they experience different from teaching other topics, they added.

The teachers were asked to reveal their view on what a good mathematics teacher is. Most of them replied emphasizing on problem solving skills. One of them significantly revealed that to be a good mathematics teacher he or she must be pedagogically rich.

When they were asked about their perception on pedagogical knowledge all of them respondedwith an enthusiasm that it was art of teaching or teaching technique through which the students can understand easily their required content knowledge. Everybody acknowledged the importance of pedagogical skill and they were having lack of it in general and particularly in geometry. In the reply when asked how it can be developed, they stated their belief that attending lecture, doing training course, designing lesson plan, pedagogical knowledgecould be developed. One significantly stressed on relating contents with day to day life activities which might need some models to be prepared. Most of them believed that teaching experience was not a leading factor to enrich pedagogical skills; that might be a supporting factor.

When the teachers were asked how both the content knowledge and pedagogical knowledge help during class room session, two of them stated that without pedagogical knowledge effective teaching could never be taken place as they use to experience, and one of them asserted that without content knowledge pedagogical knowledge is irrelevant. But, other two of them mentioned that for effective teaching and learning, both types of knowledge were parallel important.

\section{B. Results of Teaching Episode}

Each of the teachers was asked to take a class on regular lesson of ninth standard geometry and which was held in a CBSE affiliated public school. As the teachers were experienced and use to teach on a regular basis in secondary level, they agreed to take a class on any of the weekdays. Only 30 minutes was given to each of the teachers for the assigned class where the strength was 35 . As they were requested they submitted lesson plans in brief of concerned topics.

All the teachers had been found to be confident in entry, approach and in delivery. All of them used to take first few minutes to recapitulate a bit previous idea. As teaching aids text book, lesson plan and pointer were used; however, one of 
them carried some geometric apparatus out for accurate construction or drawing of geometric figures. The lessons given to the teachers were on circle and areas of parallelograms. After recapitulation each of them started proof of theorem concerned to their lesson followed by some examples from the text book. All the teachers performed confidently with procedural fluency and nobody was found to be incorrect in contents. However, one of them was trying to relate the geometric situation with day to day life activities and emphasized in connectedness on properties within the figure. Also students were found to be more involved in his class.

Most of the teachers proved the theorem with traditional pedagogical approach through some steps-drawing figure-given - to prove-construction (if necessary)proof; thereafter, picked up an example from text book related to the theorem. One student asked one of them how it could be known about the necessity of additional construction in the figure drawn from the given statement. In the reply, he thought for few seconds, and explained latter, how the additional construction was required to support connectedness on relevant properties in the figure.

\section{Results of the Post-Teaching Episode}

After successful completion of teaching episode all of the teachers wanted to assess students' learning outcome through giving exercise to them, but due to time constrain that couldnotbe done. Two teachers were disappointed regarding the students' inattentiveness. Significantly, one of them said that most of the students were interactive and he enjoyed that. Most of the teachers said that majority students of any standard use to dislike geometry for which they could not perform well in this segment of mathematics. More significantly, all the teachers acknowledged about the necessity of preparation for a mathematics class in general, and particularly for geometry segment.

Immediately after the completion of the teaching session when students' feedback was sought on their learning experience, response range was found to be from good to excellent. Almost all the students showed liked one teacher, who explained geometrical phenomenon with the help of some physical examples from everyday life activities which usually helps them in visualization. Few from the rest were good and the others were very good like their regular teacher, they said.

\section{DISCUSSION}

The interview and teaching episodes for the teachers who consented to join reflects that their pedagogical knowledge in mathematics is quite limited. During teaching episode everybody seems to follow methodically with procedural fluency, yet they were not satisfied themselves experiencing a lack of pedagogical skill. They were experienced and some of them were trained, but still found to be lacking in student-oriented teaching from their acknowledgement. Two pre-service training holders opined significantly that during training tenure they could not develop pedagogical skill rather, they built up a bit the same through teaching experience.Therefore, could it be considered that the teaching experience might not lead to develop pedagogical skills? Even, could it be considered that the teachers training programs are no longer effective to develop teachers' pedagogical skills for effective teaching outputs? A special attention need to be paid in this area redefining concept of teachers training and redesigning its course contents for effective pedagogical outputs.

Another challenge faced by mathematics teachers is gathering mathematical content knowledge, for which most of the teachers prepare their lessons from text book. Text book is for instructional use which consists of limited ideas and inadequate examples. To be dependent on it fully, teachers will need to assess textbook as teaching program, how perfectly textbook visualize students that a teacher must educate, day-to-day real life activities/ problems he or she will face, the feasibilities of various class room activities and more importantly, preparation of models which is not easy task based only on text book. If text book is like a machine then the teachers are engineered for a specific purpose, and that is why they should be armed with adequate knowledge to achieve the purpose, for which they can go through other relevant reference books and discussion with right persons.

In a reply most of the teachers revealed that good mathematics teacher implied he or she could solve various difficulty leveled problems.But when a teacher is evaluated, then his/her performance in transferring knowledge to students during the class room session is assessed. Teachers use to think to be not good enough despite maintaining regularity and sincerity in their job. To feel much better they need to be enlightened through the workflowstrengthening knowledge transferring domainstressing more and more on pedagogical knowledge for bridging the gap between contents and students (Fig. 2).

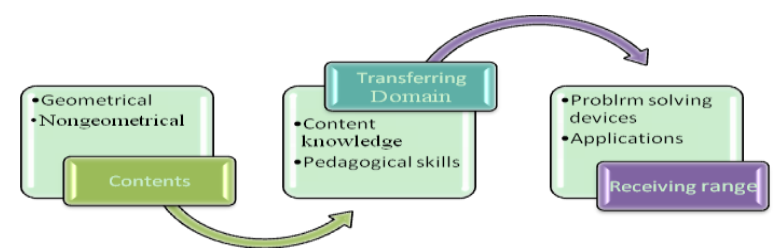

Fig. 2. Bridging gap between contents and students.

Thus, if the teachers experience lacking of pedagogical knowledge which affects in effective learning session,for both having long teaching experience and trained teachers, then would it be possible for students to meet the policy makers expectation level? As mathematics a key-subject, would it not create a challenge for students to compete with hi-tech world?

\section{CONCLUSION}

In light of the findings in this study, pedagogical skill development is a big challenge for mathematics teachers in secondary level in the district. In spite of being trained they use to face this challenge, which indicates urgent needs of drastic modifications for effective pedagogical outputs through redefining and redesigning the entire teachers training courses.

Moreover, as findings in this study it reveals that in spite of having long teaching experience they may not have adequate 
content as well as pedagogical knowledge.In this context, teachers will have to take up the challenges themselves to create a new dimension in teaching mathematics with self-developed methods and innovative devices stressing on the components shown in the radial cycle (Fig. 1), so that the objectives of introducing mathematics in schools could be fulfilled to compete with the high-tech world.

\section{REFERENCES}

[1] NCTM, National Council of Teachers of Mathematics, Curriculum and Evaluation Standards for School Mathematics, Reston, VA: NCTM, 1989.

[2] NCTM, National Council of Teachers of Mathematics, Principles and Standards for School Mathematics, Reston, VA: NCTM, 2000.

[3] E. A. Silver, H. Ghousseini, D. Gosen, C. Charalambous, and B. T. F. Strawhun, "Moving from rhetoric to praxis: Issues faced by teachers in having students consider multiple solutions for problems in the mathematics classroom," Journal of Mathematical behavior, vol. 24, pp. 287-301, 2005.

[4] School Mathematics Study Group, "Correlates of mathematics achievement: Teacher background and opinion variables," in J. W. Wilson and E. A. Begle (Eds.), NLSMA Reports, no. 23, part A, Palo Alto, CA: Author, 1972.

[5] T. A. Eisenberg, "Begle revisited: Teacher knowledge and student achievement in algebra," Journal for Research in Mathematics Education, vol. 8, pp. 216-222, 1977.

[6] General Accounting Office, New directions for federal programs to aid math and science teaching (GAO/PEMO-85-5), Washington, DC: Author, 1984.

[7] E. Fennema and M. L. Franks, "Teachers' knowledge and its impact," in D. A. Grouws (Ed.), Handbook of research on mathematics teaching and learning, pp. 147-164, NY: Macmillan Publishing Company, 1992.

[8] L. Shulman, "Knowledge and teaching: Foundations of the new reform," Harvard Educational Review, vol. 57, pp. 1-22, 1987.

[9] T. J. Lovat, "The role of the 'teacher' coming of age?" Australian Council Deans of Education, Discussion Paper, pp. 11-12, 2003.
[10] Shulman and S. Lee, "Those who understand: Knowledge growth in teaching," Educational Researcher, vol. 17, no. 1, pp. 4-14, 1986.

[11] A. H. Schoenfeld, Dilemmas/Decisions: Can we model teachers' on-line decision making? 2005.

[12] R. Davis, "Mathematics teaching with special reference to epistemological problems," Journal of Research and Development in Education, Monograph, no. 1, 1967.

[13] Deborah, "Knowledge and reasoning in mathematical pedagogy: Examining what prospective teachers bring to teacher education," Michigan State University, 1988.

[14] NSW, Pedagogy for the future: Three year strategic submission NSW, Sydney: NSWDET Quality Teacher Project, 2000.

[15] ACDE, Response to the Commonwealth Review of Teaching and Teacher Education, Canberra: Australian Council of Deans of Education, 2002.

[16] V. Hiele, Structure and Insight: A Theory of Mathematics Education, Orlando, FL: Academic press, 1986

[17] V. H. Geldof, "The didactics of geometry in the lowest class of secondary school," in D. Fuys, D. Geddes, and R. Tiscler (Eds), English translation of selected writings of Dina Van Hiele-Geldof and Pierre M. Van Hiele, pp. 1-214, 1984.

[18] M. L. Crowley, "The van Hiele model of the development of geometric thought," in M. Montgomery Lindquist (Ed.), Learning and teaching Geometry, K-12, 1987 Yearbook of theNational Council of the Teachers of Mathematics, pp. 1-16, Reston, VA: National Council of Teachers of Mathematics, 1987.

[19] K. M. Thompson, "Geometry students' attitudes toward mathematics: An empirical investigation of two specific curricular approaches," Master's Thesis, California State University Dominguez Hills, USA, 1993.

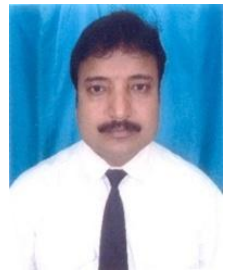

Gunendra Chandra Das is an assistant professor. He lives in Assam down town University. He got M.Sc in mathematics, and B.Ed. He is pursuing $\mathrm{PhD}$. He has five publications in the field of mathematics education He interested in mathematics education. 